\title{
Research on the Development Mechanism of Postpeak Cracks in Sandstone under Different Confining Pressures
}

\author{
Jihua Zhang $\mathbb{D}^{1},{ }^{1}$ Lianguo Wang $\mathbb{D}^{2},{ }^{2}$ Yun Dong ${ }^{\mathbb{D}},{ }^{1}$ Yadong Chen, ${ }^{1}$ Yang Jiang, \\ Huasheng Sun $\left(\mathbb{1},{ }^{1}\right.$ Jiarui Chen $\left(\mathbb{1},{ }^{1}\right.$ and Yuqing Fan ${ }^{3}$ \\ ${ }^{1}$ Faculty of Architecture and Civil Engineering, Huaiyin Institute of Technology, Huaian, Jiangsu 223001, China \\ ${ }^{2}$ State Key Laboratory for Geomechanics and Deep Underground Engineering, China University of Mining \& Technology, \\ Xuzhou, Jiangsu 221116, China \\ ${ }^{3}$ School of Mining Engineering, Guizhou University of Engineering Science, Bijie, Guizhou 551700, China
}

Correspondence should be addressed to Yun Dong; hadyun@163.com

Received 9 January 2019; Accepted 17 April 2019; Published 2 May 2019

Academic Editor: Surajit Kumar Paul

Copyright (C) 2019 Jihua Zhang et al. This is an open access article distributed under the Creative Commons Attribution License, which permits unrestricted use, distribution, and reproduction in any medium, provided the original work is properly cited.

\begin{abstract}
Water inrush happens occasionally during deeper roadways excavation. It is mainly due to the lack of understanding in the formation and development mechanism of cracks and its spatial distribution pattern under ground stress. In view of this, this paper used different stress levels to represent the fracture state of different parts of the surrounding rock of the deep roadway; CT detection technique is used to scan the fractured sandstone in the postpeak state; and the CT images under different confining pressures are thus obtained. The geometrical parameters such as area, length, and width of the crack are used to describe the distribution patterns based on CT images processing technique and statistical principle. These patterns are then analyzed under varying postpeak stress levels and confining pressures. The result shows that, as the area, length, and width of the cracks get larger, number of cracks increases with decreasing stress level; at different stress levels, sandstone crack area probability density, crack length probability density, and crack width probability density form exceptional, linear, and Gaussian distribution, respectively. The amount of confining pressure affects the size of cracks and the extent of expansion. This means that the higher the confining pressure is, the easier the internal crack will be penetrated and expanded and the bigger the cracks are, and the number of cracks gets lesser. Such research results can be used to describe the propagation and evolution law of cracks under different stress states of postpeak rock, which also provide an important basis for further analysis of its permeability and the stability of roadway surrounding rock.
\end{abstract}

\section{Introduction}

Fractures in rock are major channels for groundwater seepage. After excavation of roadway, adjustment of stress balancing would cause changes of fracture field, which is the source of common disasters of tunnel exploration such as fracture water, aquifer, collapse column, and fault [1-3]. Objects of surrounding rock of roadway timbering are ruptured rock mass in the back of peak, and underground water enters into roadway through underground watercourse, causing reduction of bearing capacity of timbering, failures of anchoring, and unstable roadway. In addition, under the effects of crustal stress, surrounding rock of roadway has different permeability in different space regions, which is closely related to number of internal fractures, space distribution, and distribution characteristics. Therefore, study on distribution rules of cracks in the back of rock peak under different stress and their quantitative expression methods has important guiding significance and application value to evaluate forms and permeability of internal cracks of rock in the back of peak and reveal disaster-causing mechanism of transfusion [4-6].

For formation and expansion mechanism of internal cracks of rock, scholars had many works. At the very beginning, they studied expansion of crack by establishing theoretical models [7-9] and then introduced rock mechanics test, numerical simulation, and CT detection. Zhao Yanlin [10-12], Wong [13-15], Nazife Erarslan [16], and Yang Shengqi et al. [17-19] studied expansion rules of rock or rock precrack with different parameters (crack density, crack porosity, crack dip angle, crack length, and crack gap) through experiment and 




$a$ - Residual strength zone; $b$ - Strain softening zone; $c$-Plastic zone; $d$-Elastic zone

FIGURE 1: Relationship between loose state of surrounding rock and the stress-strain curve of rock.



FIGURE 2: Rock samples after processing.

their influence on rock mechanical property. Through DDM, discrete element, RFPA, and microscopic damage numerical method, Camonesa [20], Liang Zhengzhao [21], Yang Shengqi [22], Li Lianchong [23], Wang [24], and Lu Yinlong et al. $[25,26]$ studied expansion rules of rock crack and fracture, as well as destruction process of rock test pieces. Moreover, Ren Jianxi [27], Li Yanchun [28], Yin Xiaotao [29, 30], Wang Chuanyang [31], and Yang Yongming et al. [32] adopted CT scanning technology to analyze production and expansion of internal crack of rock under loading process, and their influence on rock mechanical property. The research results had important significance to reveal expansion mechanism and rules of rock crack under effects of external applied load. However, due to anisotropy of rock material, distribution changes of internal crack under the effects of external applied load would be more complex, and meanwhile, there are no quantitative description methods for quantity, form and space distribution of crack [33-36], thus making people have difficulties to grasp distribution characters of cracks under effects of crustal stress and their influence factors. To study number and geometrical morphology characteristics of crack in the back of peak under different crustal stress, the essay adopted CT detection technology to scan ruptured sandstone under different crustal stress on the basis of common triaxial test to obtain CT image of crack distribution, used image processing techniques and principle of statistics to extract geometrical morphology of crack distribution in the back of sandstone, and employed geometrical parameters including width, length, and area of crack to describe crack distribution characteristics and reveal influence of confining pressure size and stress level in the back of peak on geometrical characteristics of crack in the back of peak.

\section{CT Scanning Test of Crack}

After roadway is excavated, due to readjustment and distribution of surrounding rock stress, stress state in the inside of surrounding rock of roadway would be different, thus causing damage degree of internal surrounding rock in different positions has big differences. Generally speaking, the closer to the superficial part of surrounding rock, the bigger the damage degree will be; thus different stress levels of rock in the back of peak can be used to stand for fracture state in different positions around surrounding rock, which is as shown in Figure 1.

The material that the test used is sandstone in certain coal mine of Huaibei mining group. Test pieces were processed into cylinders with a diameter of $50 \mathrm{~mm}$ and a height of $100 \mathrm{~mm}$. 60 samples were processed, and 27 of them were selected for triaxial damage test and CT scanning test under different confining pressure and stress levels in the back of peak. To avoid test errors, unevenness degree of the two planes of processed test pieces could not surpass $0.005 \mathrm{~mm}$, irregularity degree of each plane cannot exceed $0.02 \mathrm{~mm}$, and angle between the vertical line of each plane with the central line cannot surpass $0.25^{\circ}$. Test samples are as shown in Figure 2.

Based on common triaxial compression test, three groups of confining pressure stresses were designed: $2 \mathrm{MPa}, 2.5 \mathrm{MPa}$, and $3 \mathrm{MPa}$, corresponding to peak point, intermediate point of strain softening, and residual strength point of stress level in the back of peak, respectively (A, B, and C in Figure 1). For the convenience of operation, postpeak stress levels were $90 \%, 65 \%$, and $40 \%$ of peak strength, respectively, and corresponding mean intensity was shown in Table 1. 




(a) Industrial CT



(b) Cross section



(c) Longitudinal section

FIGURE 3: ACTIS300-320/225 industrial CT and the scanned pictures of rock specimen.

TABLE 1: CT scanning experiment scheme for post-peak sandstone.

\begin{tabular}{lccc}
\hline $\begin{array}{l}\text { Confining } \\
\text { pressure/MPa }\end{array}$ & Peak intensity (A) & $\begin{array}{c}\text { Post-peak stress state /MPa } \\
\text { Strain softening (B) }\end{array}$ & Residual strength (C) \\
\hline 2 & 94 & 68 & 42 \\
2.5 & 96 & 70 & 43 \\
3 & 98 & 71 & 44 \\
\hline
\end{tabular}

ACTIS300-320/225 industry CT (as shown in Figure 3(a)) was adopted to scan from of ruptured space of test pieces (see in the testing program in Table 1) under different stress levels to obtain CT images of crack distribution under different stress states (as shown in Figures 3(b) and 3(c)). ACTIS300$320 / 225$ industry CT was mainly applied in nondestructive testing and flaw detection of industrial products, and its detection principles are as shown in Figure 4. It can closely and accurately represent internal three-dimensional structure of objects and quantificationally provide internal physical and mechanical properties such as position and size, density changes, and level of defected positions, shape, and accurate size of difference type structure, as well as internal impurities and distribution of objects.

For rock postpeak test pieces scanned by CT, cut out one pieces from up to bottom with an interval of $1 \mathrm{~mm}$ and cut out 100 levels in total. Since the CT images are $1024 \times 1024$ grey-scale maps, the grey scale of changes within the scope of $0 \sim 255$. To extract information of rock postpeak crack, CT images should have follow-up treatment. At present, analysis of CT images of rock is mainly to observe whether it has defects like holes and crack in the inside through images so as to roughly judge their positions, but it fails to make use of micro physical information included by the images. If contrast ratio of CT images is low, boundaries between crack and hole would be not obvious at all, and together with noises, sensory information is hard to effectively reveal macro and micro information hidden in images. Most analysis of CT data described evolution rules of crack in the inside of rock through mean value CT data or variance changes and often neglected unevenness of rock. Therefore, to highlight useful image information of rock such as holes and crack and enhance contrast ratio of images, CT images should have data treatment. Adopting Matlab software which used self-programmed procedures, the essay obtained the twodimensional diagram including crack postpeak geometrical morphology through histogram enhancement of CT image, median filter noise reduction, and OTSU threshold segmentation and eliminated remaining isolated black and white noisy points through opening and closing operation of mathematical morphology so as to obtain binary images which can reflect postpeak crack form and distribution of sandstone, which is as shown in Figure 5. At last, it had edge detection through Canny operator to obtain microstructure outline images of postpeak sandstone with white standing for boundary between holes and crack with rock particles, just as shown in Figure 6.

\section{Characterization Methods of Rock Crack}

Mechanical behaviors of rock material has nonlinearity; thus to study postpeak distributions rules of crack, it is necessary to introduce a series of parameters to describe irregular crack forms, including distance, shape factor, length, width, and area, to have quantitative description and statistics of the above processed image crack forms.

(1) Distance. To avoid errors generated by conventional measurement of images, introduced geodesic distance to realize length measurement of irregular geometrical shape, and the definition is as follows [35]:

$$
L(X)=\sup _{a, b \in X} d_{X}(a, b)
$$

In the formula, supstands for supremum, $d_{\mathrm{X}}(a, b)$ is the geodesic distance between $a$ and $b$ in the image, standing 




Figure 4: Detection principle of industrial CT scanning system.


FIGURE 5: Binary images of cracks distribution of postpeak sandstone.

for that at least there is a shortest length of connection arc $d_{\mathrm{X}}(a, b)$ between $a$ and $b$. Differences of geodesic distance and Euclidean distance are shown in Figure 7.

(2) Shape Factor. Rock postpeak crack includes various irregular physical characteristics. To depict the geometrical shapes reasonably, it is necessary to introduce shape factors, which can be expressed by the following formula [29]:

$$
F F(X)=\frac{U(X)}{2 \sqrt{\pi A(X)}}
$$

In the formula, $U(X)$ is the perimeter of irregular geometrical shape of the study area; $A(X)$ is the acreage of the study area. If the study area is round, $F F$ value is 1; if shape of $\mathrm{X}$ significantly deviates from roundness, FF value will be bigger. Perimeter of the study area is obtained by the boundary extraction algorithm of the mathematical morphology; that is to say, $U(A)=(A-(A \Theta B))$, indicating results of image $A$ subtracting the part which is eaten off by $B$, which is as shown in Figure 8 ; the acreage of the study area can be obtained by making the element number in the crack area multiplying acreage of the resolution element, which is related to precision of measuring instrument.

(3) Crack Width. When estimating crack width in the study area, crack in curve form can be divided into several rectangular $L$ sections to study, just as shown in Figure 9. In the figure, the solid line range is the designated area when there is no crack, while the imaginary line area is the crack range and $L_{1}$ and $W_{1}$ are length and width when there is no crack, respectively, and $L$ and $W$ are length and width, respectively, after equivalent processing. 

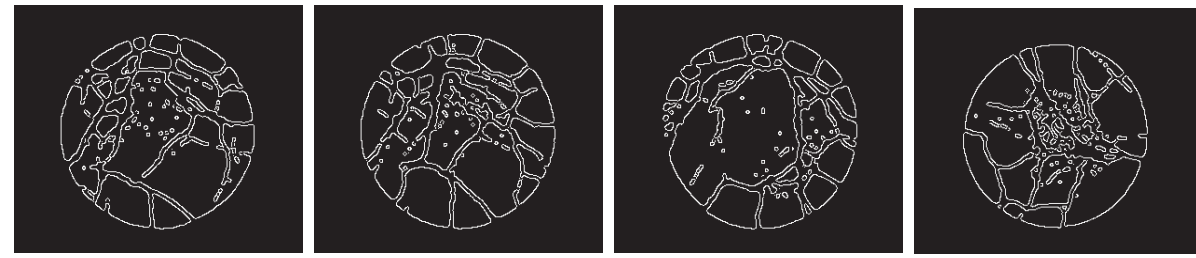

FIGURE 6: Edge detection results of cracks distribution of postpeak sandstone.


FIgURE 7: Measurement effect of geodesic distance and Euclidean distance.


FIGURE 8: Boundary extraction algorithm of binary morphology.

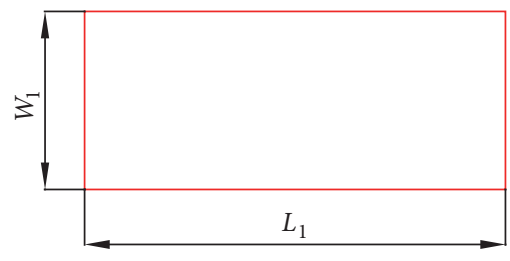

(a) No crack



(b) After crack

FIgURE 9: Calculation of crack width.

By use of resolution ratio of CT machine and CT numbers when scanning the rock crack area, width of crack can be calculated [36]:

$$
W=\frac{S \times\left(H_{0}-H\right)}{L \times\left(H_{0}+1000\right)}
$$

In the formula, $S$ is the acreage of the study area and $S=$ $L_{1} \times N_{1} ; H_{0}$ is the average value of CT number when there is no crack in the study area; $H$ is the average value of $\mathrm{CT}$ number after there is crack in the study area; and -1000 is CT number of air.

\section{Test Results and Analysis}

Adopting the above characterization methods for crack form used self-compiled program to extract and gather all crack geometrical morphology information in CT images of 


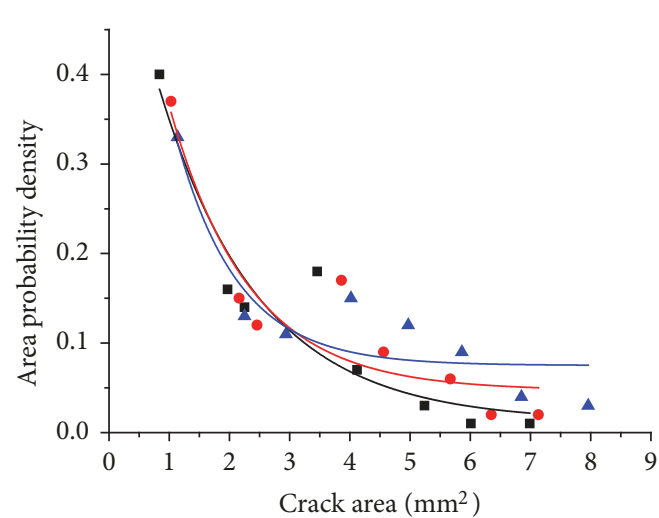

- Peak strength

- Strain softening

- Residual strength

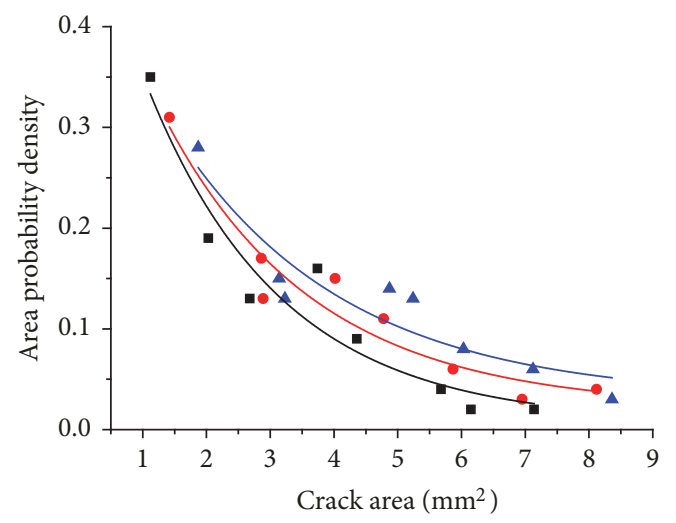

- Peak strength

- Strain softening

- Residual strength

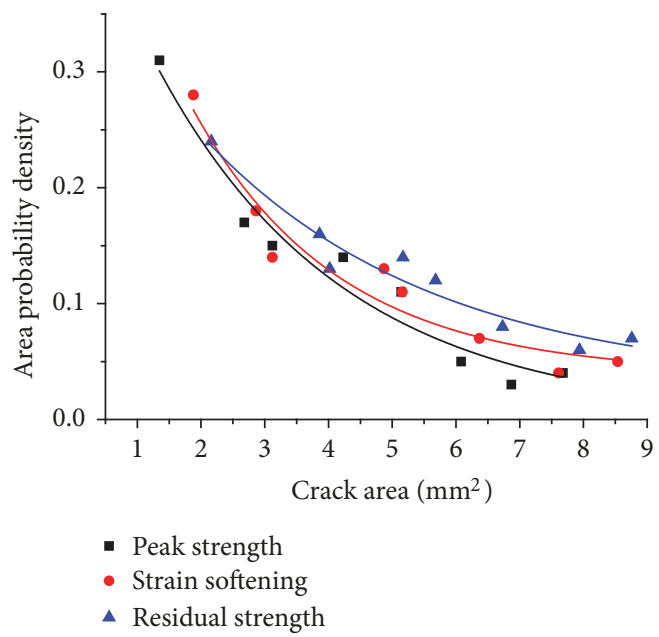

(b) $2.5 \mathrm{MPa}$

(c) $3 \mathrm{MPa}$

FIGURE 10: Distribution probability of cracks area under different stress level for postpeak rock.

processed rock postpeak and analyzed influence of confining pressure size and postpeak stress level on geometrical characteristics of above crack distribution.

(1) Distribution Rules of Crack Area. Divide crack areas obtained by scanning test pieces with CT into 8 areas from small to big and calculate probability of number of crack in each area. Distribution of crack area under different stress level is as shown in Figure 10. In the figure, peak strength, strain softening, and residual strength stand for $A, B$, and $C$ in the above test, respectively.

From Figure 10, under the same confining pressure, different postpeak stress level and distribution of crack area have big differences, and distribution of postpeak sandstone crack area under different confining stress conditions is also different. In regard of the three kinds of postpeak stress levels, namely, peak strength $(A)$, strain softening $(B)$, and residual strength $(C)$, when confining pressure is $2 \mathrm{MPa}$ crack with an area less than $3 \mathrm{~mm} 2$ makes up $70 \%, 64 \%$, and $57 \%$; and crack with an area bigger than $5 \mathrm{~mm} 2$ is $5 \%, 10 \%$, and $16 \%$, respectively. When confining pressure is $2.5 \mathrm{MPa}$, crack with an area less than $4 \mathrm{~mm} 2$ makes up $67 \%, 61 \%$, and $56 \%$; and crack with an area bigger than $6 \mathrm{~mm} 2$ makes up $4 \%, 7 \%$, and $9 \%$; when confining pressure is $3 \mathrm{MPa}$, crack with an area smaller than $5 \mathrm{~mm} 2$ makes up $77 \%, 73 \%$, and $53 \%$; and crack with an area bigger than $7 \mathrm{~mm} 2$ makes up 4\%, 9\%, and $13 \%$. Thus, we can know that, with increase of confining pressure, postpeak crack area of sandstone will gradually shift to the area with big crack, while with decrease of postpeak stress level of sandstone, small crack would continuously slip, expand and run through, and gradually shift to big crack, causing crack area gradually increase. By fitting test data, it can found that distribution of crack area nearly presents the distribution of exponential decrease and can be expressed by the following formula:

$$
y=y_{0}+A_{0} e^{-x / t}
$$

In the formula, $y_{0}, A_{0}$, and $t$ are undetermined parameters, and values of various undetermined parameters under different stress levels are as shown in Table 2. 


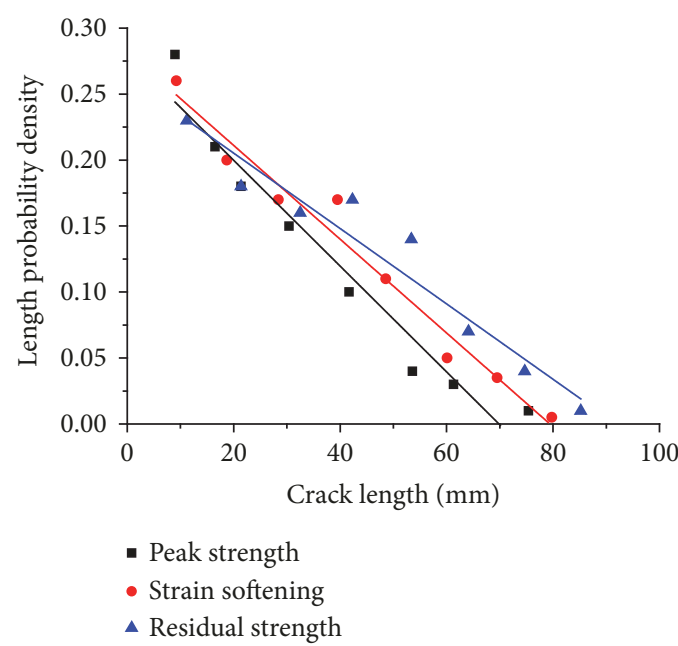

(a) $2 \mathrm{MPa}$

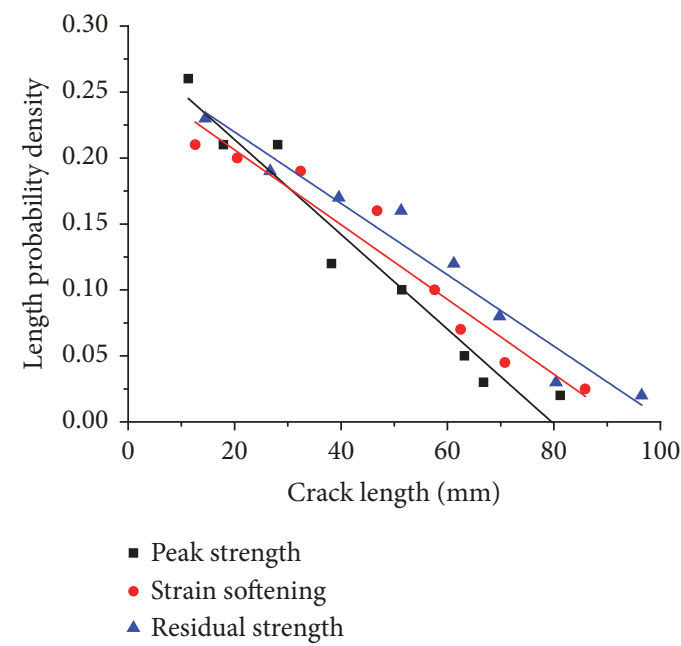

(b) $2.5 \mathrm{MPa}$

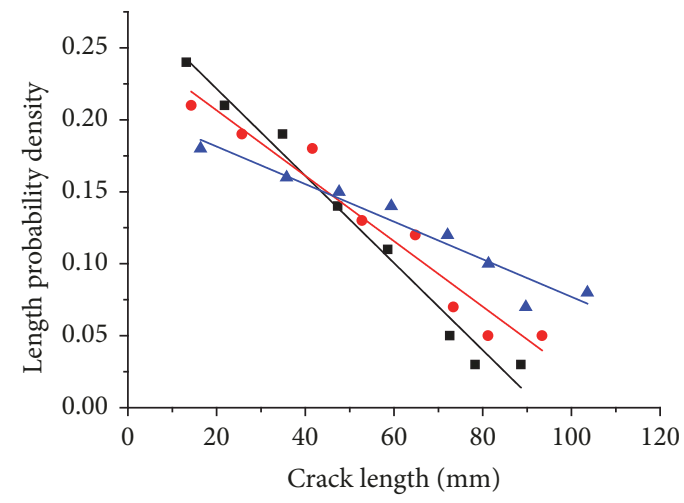

- Peak strength

- Strain softening

$\Delta$ Residual strength

(c) $3 \mathrm{MPa}$

FIGURE 11: Distribution probability of cracks length under different stress level for postpeak rock.

TABLE 2: Fitting parameters of cracks-area distribution under different stress level for post-peak sandstone.

\begin{tabular}{|c|c|c|c|c|c|c|c|c|c|}
\hline \multirow{3}{*}{ Parameter } & \multicolumn{3}{|c|}{ Confining pressure } & \multirow{2}{*}{\multicolumn{3}{|c|}{$\begin{array}{c}\text { Confining pressure } \\
2.5 \mathrm{MPa}\end{array}$}} & \multirow{2}{*}{\multicolumn{3}{|c|}{$\begin{array}{c}\text { Confining pressure } \\
3 \mathrm{MPa}\end{array}$}} \\
\hline & \multicolumn{3}{|c|}{$2 \mathrm{MPa}$} & & & & & & \\
\hline & $A$ & $B$ & C & $A$ & $B$ & C & $A$ & $B$ & $C$ \\
\hline$y_{0}$ & 0.012 & 0.047 & 0.075 & 0.007 & 0.021 & 0.031 & 0.002 & 0.039 & 0.03 \\
\hline$A_{0}$ & 0.614 & 0.677 & 0.755 & 0.555 & 0.507 & 0.459 & 0.473 & 0.52 & 0.375 \\
\hline$t$ & 1.668 & 1.32 & 1.025 & 2.108 & 2.373 & 2.686 & 2.925 & 2.277 & 3.607 \\
\hline
\end{tabular}

(2) Distribution Rules of Crack Length. Under different postpeak stress levels, distribution of crack length is as shown in Figure 11, and it is observed that, under different postpeak stress levels, with decrease of stress level, crack length will gradually increase and its distribution probability density presents distribution of linear type decline. In regard of three kinds of postpeak stress levels, namely, peak strength $(A)$, strain softening $(B)$, and residual strength $(C)$, when confining pressure is $2 \mathrm{MPa}$, crack with an area smaller than $30 \mathrm{~mm}$ makes up $67 \%, 63 \%$, and $41 \%$, respectively; and crack with an area bigger than $50 \mathrm{~mm}$ takes up $8 \%$, 9\%, and $26 \%$, respectively. When confining pressure is $2.5 \mathrm{MPa}$, crack with an area smaller than $40 \mathrm{~mm}$ makes up $80 \%, 60 \%$, and $59 \%$, respectively, and crack with an area bigger than $60 \mathrm{~mm}$ makes up $10 \%, 14 \%$, and $25 \%$, respectively; when confining pressure is $3 \mathrm{MPa}$, crack with an area smaller than $60 \mathrm{~mm}$ makes up $89 \%, 71 \%$, and $63 \%$, respectively, and crack with an area bigger than $80 \mathrm{~mm}$ makes up $3 \%, 11 \%$, and $15 \%$, respectively. Thus, we can see that postpeak stress level has a great influence on extension and distribution of crack length, 


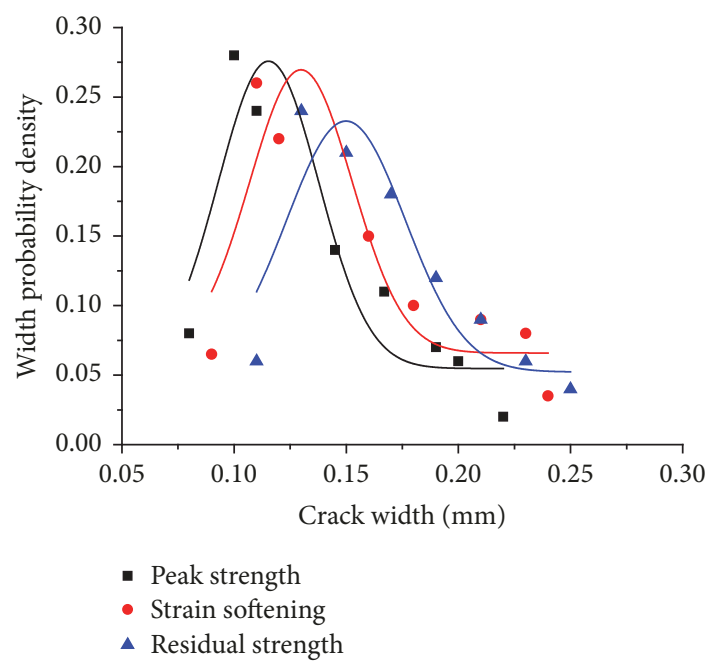

(a) $2 \mathrm{MPa}$

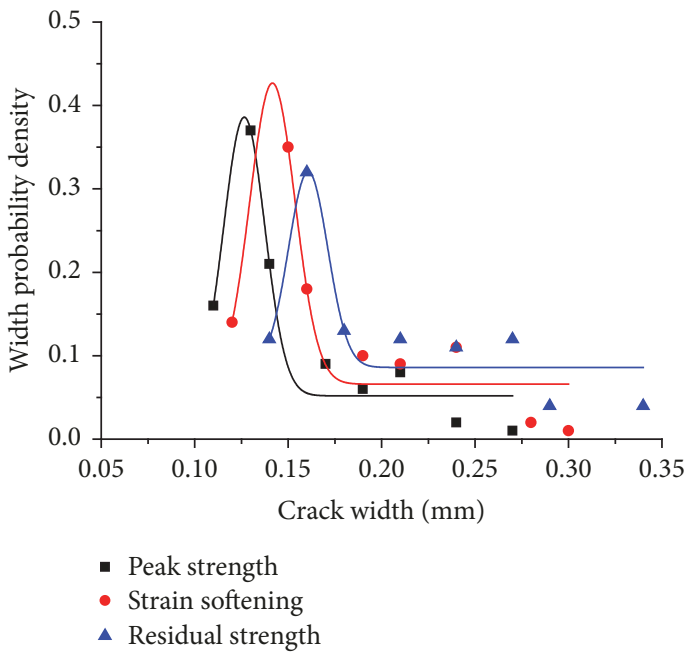

(b) $2.5 \mathrm{MPa}$

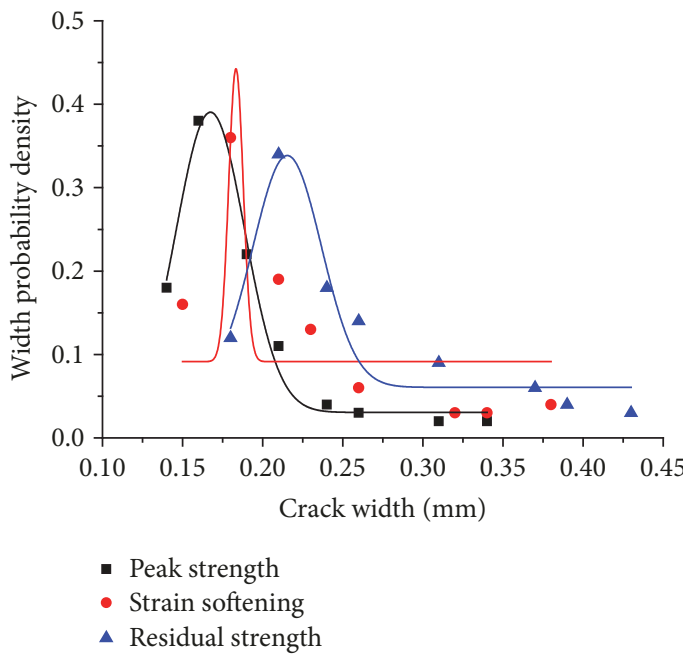

(c) $3 \mathrm{MPa}$

FIGURE 12: Distribution probability of cracks width under different stress level for postpeak rock.

and size of confining pressure affects slope or decides speed and extension direction of transition from small crack to big crack.

(3) Distribution Rules of Crack Width. Under different postpeak stress levels, distribution of crack width is as shown in Figure 12. Through fitting of test data, it can be seen that distribution probability of crack width nearly presents Gaussian distribution, which can be expressed with the following formula:

$$
y=y_{1}+\frac{A_{1}}{w \sqrt{\pi / 2}} e^{-2\left(\left(x-x_{c}\right) / w\right)^{2}}
$$

In the formula, $y_{1}, A_{1}, x_{c}$, and $w$ are undermined, and values of various undetermined parameters under different postpeak stress levels are as shown in Table 3.

From Figure 12 and Table 3, we can see, under the same confining pressure, with decrease of postpeak stress level, peak point of fitting curve would gradually increase; that is to say, crack width gradually increases; for example, when confining pressure is $3 \mathrm{MPa}, x_{c}$ value of $A, B$, and $C$ is $0.167,0.183$, and 0.215 , respectively. Under the same postpeak stress level, with increase of confining pressure, peak point will increase correspondingly, for example, when they are in residual strength $C$, under the three kinds of confining pressure conditions, $x_{c}$ of peak point is $0.15,0.161$, and 0.215 , respectively, and influence of postpeak stress level on postpeak crack width is bigger than that of confining pressure. In brief, with increase of confining pressure, narrow crack would gradually reduce and transform into wide crack.

\section{Conclusions}

By CT scanning sandstone test pieces under different postpeak stress levels, distribution rules of sandstone postpeak crack can be obtained:

(1) Under different confining pressure, sandstone postpeak crack area probability density, crack length probability, 
TABLE 3: Fitting parameters of cracks width distribution under different stress level for post-peak sandstone.

\begin{tabular}{|c|c|c|c|c|c|c|c|c|c|}
\hline \multirow{3}{*}{ Parameter } & \multicolumn{3}{|c|}{ Confining pressure } & \multicolumn{3}{|c|}{ Confining pressure } & \multicolumn{3}{|c|}{ Confining pressure } \\
\hline & \multicolumn{3}{|c|}{$2 \mathrm{MPa}$} & \multicolumn{3}{|c|}{$2.5 \mathrm{MPa}$} & \multicolumn{3}{|c|}{$3 \mathrm{MPa}$} \\
\hline & $A$ & $B$ & $C$ & $A$ & $B$ & $C$ & $A$ & $B$ & $C$ \\
\hline$y_{1}$ & 0.055 & 0.066 & 0.052 & 0.052 & 0.066 & 0.086 & 0.031 & 0.091 & 0.061 \\
\hline$A_{1}$ & 0.045 & 0.046 & 0.053 & 0.022 & 0.024 & 0.021 & 0.043 & 0.009 & 0.043 \\
\hline$x_{\mathrm{c}}$ & 0.115 & 0.130 & 0.150 & 0.127 & 0.142 & 0.161 & 0.167 & 0.183 & 0.215 \\
\hline$w$ & 0.012 & 0.012 & 0.012 & 0.009 & 0.011 & 0.006 & 0.019 & 0.004 & 0.015 \\
\hline
\end{tabular}

and crack width probability density present exponential distribution, linear distribution, and Gaussian distribution.

(2) With increase of confining pressure, crack area probability density, crack length probability, and crack width probability density gradually shift into big area, but probability density value would be smaller, indicating that confining pressure affects crack size and extension direction; that is to say, the bigger the confining pressure, the easier big crack will come into being, but the number of crack would reduce.

(3) With decrease of postpeak stress level, area, length, and width of crack would continuously increase and number of crack would also increase; small crack would slip, extend, run through, and gradually transform into big crack.

\section{Data Availability}

The data used to support the findings of this study are included within the article.

\section{Conflicts of Interest}

The authors declare that there are no conflicts of interest regarding the publication of this paper.

\section{Acknowledgments}

This work was supported by the National Natural Science Foundation of China (Projects nos. 51708245, 51808246, 51804129, and 51404245), the Scientific and Technological Guidance Project of Jiangsu Construction System (Projects nos. 2018ZD268 and 2017ZD246), the Science and Technology Project of the Ministry of Housing and UrbanRural Construction of China (Project no. 2017K6004), the Natural Science Foundation for Colleges and Universities in Jiangsu Province (Projects nos. 17KJB130003, 17KJA560001, and 17KJB620002), the Project with Science and Technology of Huaian City (Projects nos. HAG201606 and HAB201708), the Natural Science Foundation of Jiangsu Province (Projects nos. BK20160426 and BK20170457), the Department of Education Foundation of Guizhou Province (Project no. QJHKYZ[2014]273), and the Cooperation Project with Science and Technology of Guizhou Province (Project no. QKHLHZ[2016]7047).

\section{References}

[1] N. Zhang, X. L. Xu, and G. Li, "Fissure-evolving laws of surrounding rock mass of roadway and control of seepage disasters," Chinese Journal of Rock Mechanics and Engineering, vol. 28, no. 2, pp. 330-335, 2009.

[2] H. Wu, N. Zhang, W. Wang, Y. Zhao, and P. Cao, "Characteristics of deformation and stress distribution of small coal pillars under leading abutment pressure," International Journal of Mining Science and Technology, vol. 25, no. 6, pp. 921-926, 2015.

[3] G. C. Li, Z. H. Jiang, C. X. Lv, C. Huang, G. Chen, and M. Y. Li, "Instability mechanism and control technology of soft rock roadway affected by mining and high confined water," International Journal of Mining Science and Technology, vol. 25, no. 4, pp. 573-580, 2015.

[4] P. Cao, H. Lin, and T. Y. Liu, "Evolution procedure of multiple rock cracks under seepage pressure," Mathematical Problems in Engineering, vol. 1, pp. 211-244, 2013.

[5] Y. L. Zhao, P. Cao, W. H. Ma, J. Z. Tang, W. Wang, and W. J. Wang, "Coupling model of seepage-damage-fracture in fractured rock masses and its application," Zhongnan Daxue Xuebao, vol. 48, no. 3, pp. 794-803, 2017.

[6] S. Krisnanto, H. Rahardjo, D. G. Fredlund, and E. C. Leong, "Mapping of cracked soils and lateral water flow characteristics through a network of cracks," Engineering Geology, vol. 172, pp. $12-25,2014$.

[7] A. E. Green and I. N. Sneddon, "The distribution of stress in the neighbourhood of a flat elliptical crack in an elastic solid," Mathematical Proceedings of the Cambridge Philosophical Society, vol. 46, no. 1, pp. 159-163, 1950.

[8] R. P. Nordgren, "Propagation of a vertical hydraulic fracture," SPE Journal, vol. 12, no. 04, pp. 306-314, 2013.

[9] S.-C. Lin and J. F. Abel, "Variational approach for a new direct-integration form of the virtual crack extension method," International Journal of Fracture, vol. 38, no. 3, pp. 217-235, 1988.

[10] Y.-L. Zhao, W. Wan, W.-J. Wang, M. Wang, and Q.-Y. Peng, "Fracture experiments on ordered multi-crack body in rocklike materials under uniaxial compression and numerical simulation of wing cracks," Chinese Journal of Geotechnical Engineering, vol. 35, no. 11, pp. 2097-2109, 2013.

[11] Y.-L. Zhao, W. Wan, W.-J. Wang, F.-J. Zhao, and P. Cao, "Compressive-shear rheological fracture of rock-like cracks and subcritical crack propagation test and fracture mechanism," Chinese Journal of Geotechnical Engineering, vol. 34, no. 6, pp. 1050-1059, 2012.

[12] Y. L. Zhao, P. Cao, W. Wang, W. J. Wang, and Q. Y. Peng, "Rock cracks subcritical propagation test and compressionshear rheological fracture model," Journal of Central South University, vol. 45, no. 1, pp. 276-286, 2014.

[13] R. H. C. Wong, K. T. Chau, C. A. Tang, and P. Lin, "Analysis of crack coalescence in rock-like materials containing three flaws-part I: experimental approach," International Journal of 
Rock Mechanics and Mining Sciences, vol. 38, no. 7, pp. 909-924, 2001.

[14] R. H. C. Wong and S. W. Wang, "Experiment and numerical study on the effect of material property, normal stress and the position of joint on the progressive failure under direct shear," in NARMS-TAC, Mining and Roadwaying Innovation and Opportunity, pp. 1009-1016, Toronto, 2002.

[15] Y. S. H. Guo, R. H. C. Wong, K. T. Chau, W. S. Zhu, and S. C. Li, "Crack growth mechanisms from 3-D surface flaw with varied dipping angle under uniaxial compression," Key Engineering Materials, vol. 353-358, no. 4, pp. 2353-2356, 2007.

[16] N. Erarslan, "Microstructural investigation of subcritical crack propagation and Fracture Process Zone (FPZ) by the reduction of rock fracture toughness under cyclic loading," Engineering Geology, vol. 208, pp. 181-190, 2016.

[17] S. Q. Yang, D. S. Yang, H. W. Jing, Y. H. Li, and S. Y. Wang, "An experimental study of the fracture coalescence behaviour of brittle sandstone specimens containing three fissures," Rock Mechanics and Rock Engineering, vol. 45, no. 4, pp. 563-582, 2012.

[18] S.-Q. Yang, H.-W. Jing, and T. Xu, "Mechanical behavior and failure analysis of brittle sandstone specimens containing combined flaws under uniaxial compression," Journal of Central South University, vol. 21, no. 5, pp. 2059-2073, 2014.

[19] S.-Q. Yang, Y.-H. Huang, W.-L. Tian, and J.-B. Zhu, "An experimental investigation on strength, deformation and crack evolution behavior of sandstone containing two oval flaws under uniaxial compression," Engineering Geology, vol. 217, pp. 35-48, 2017.

[20] L. A. M. Camones, E. do Amaral Vargas, R. P. de Figueiredo, and R. Q. Velloso, "Application of the discrete element method for modeling of rock crack propagation and coalescence in the step-path failure mechanism," Engineering Geology, vol. 153, pp. 80-94, 2013.

[21] Z. Z. Liang, L. C. Li, S. B. Tang, and YB. Zhang, "3D numerical simulation of growth of surface crack of rock specimens," Chinese Journal of Geotechnical Engineering, vol. 33, no. 10, pp. 1615-1622, 2011 (Chinese).

[22] S.-Q. Yang, W.-L. Tian, and Y.-H. Huang, "Failure mechanical behavior of pre-holed granite specimens after elevated temperature treatment by particle flow code," Geothermics, vol. 72, pp. 124-137, 2018.

[23] L. C. Li, C. A. Tang, G. Li, S. Y. Wang, Z. Z. Liang, and Y. B. Zhang, "Numerical simulation of 3D hydraulic fracturing based on an improved flow-stress-damage model and a parallel FEM technique," Rock Mechanics and Rock Engineering, vol. 45, no. 5, pp. 801-818, 2012.

[24] S. Y. Wang, S. W. Sloan, D. C. Sheng, and C. A. Tang, "3D numerical analysis of crack propagation of heterogeneous notched rock under uniaxial tension," Tectonophysics, vol. 677678, pp. 45-67, 2016.

[25] Y. Lu and L. Wang, "Numerical simulation of mining-induced fracture evolution and water flow in coal seam floor above a confined aquifer," Computers \& Geosciences, vol. 67, pp. 157-171, 2015.

[26] Y. L. Lu, D. Elsworth, and L. G. Wang, "Microcrack-based coupled damage and flow modeling of fracturing evolution in permeable brittle rocks," Computers \& Geosciences, vol. 49, pp. 226-244, 2013.

[27] J. X. Ren, X. G. Feng, and H. Liu, "CT testing on meso-damage propagation mechanism of cracked-sandstone sample under triaxial compression loading," Journal of Xian University of Science and Technology, vol. 29, no. 3, pp. 300-304, 2009.

[28] T. C. Li and H. B. Lv, "CT real-time scanning tests on single crack propagation under triaxial compression," Chinese Journal of Rock Mechanics and Engineering, vol. 29, no. 2, pp. 289-296, 2010.

[29] X.-T. Yin, F.-N. Dang, W.-H. Ding, and H.-Q. Chen, "Morphologic measurement of crack in ct images of rock and soil," Chinese Journal of Rock Mechanics and Engineering, vol. 25, no. 3, pp. 539-544, 2006.

[30] X. T. Yin, S. L. Wang, F. N. Dang, W. H. Ding, and H. Q. Chen, "Study on fractal characteristics of sandstone damage-fracture under ct test condition," Chinese Journal of Rock Mechanics and Engineering, no. S1, pp. 2721-2726, 2008.

[31] C. Y. Wang, C. H. Yang, H. Shuai, and H. J. Mao, "CT test for evolution of mudstone fractures under compressive load," Rock and Soil Mechanics, vol. 36, no. 6, pp. 1591-1597, 2015.

[32] Y. Yang, Y. Ju, F. Li, F. Gao, and H. Sun, "The fractal characteristics and energy mechanism of crack propagation in tight reservoir sandstone subjected to triaxial stresses," Journal of Natural Gas Science and Engineering, vol. 32, pp. 415-422, 2016.

[33] Y.-M. Yang, Y. Ju, and L.-T. Mao, "Growth distribution laws and characterization methods of cracks of compact sandstone subjected to triaxial stress," Chinese Journal of Geotechnical Engineering, vol. 36, no. 5, pp. 864-872, 2014.

[34] L. Sui, Y. Ju, Y. Yang, Y. Yang, and A. Li, "A quantification method for shale fracability based on analytic hierarchy process," Energy, vol. 115, pp. 637-645, 2016.

[35] E.-K. Kim, H. Choi, K. Park, and W.-H. Kang, "Deterministic and probabilistic investigation on multiple crack interactions in a semi-infinite domain," Mathematical Problems in Engineering, vol. 2015, Article ID 305397, 9 pages, 2015.

[36] N. R. Backeberg, F. Iacoviello, M. Rittner et al., "Quantifying the anisotropy and tortuosity of permeable pathways in clay-rich mudstones using models based on X-ray tomography," Scientific Reports, vol. 7, no. 1, p. 14838, 2017. 


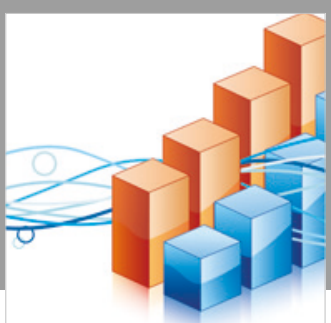

Advances in

Operations Research

\section{-n-m}
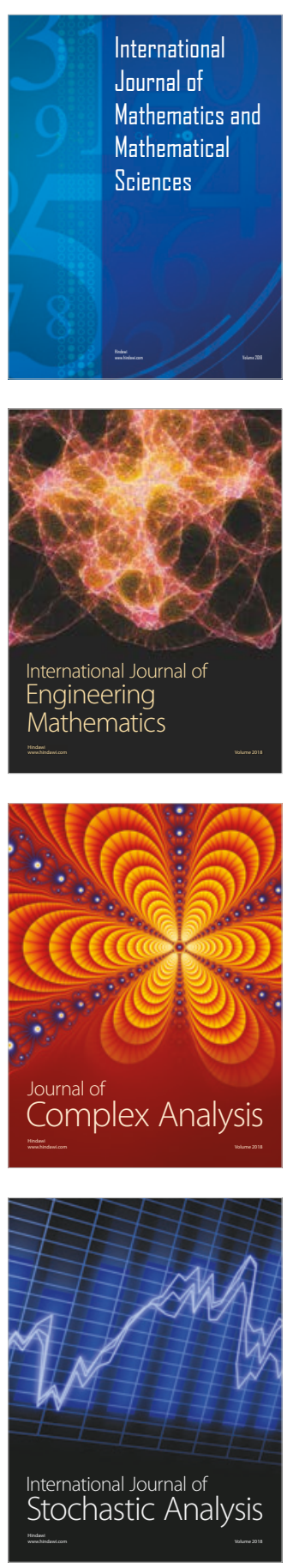
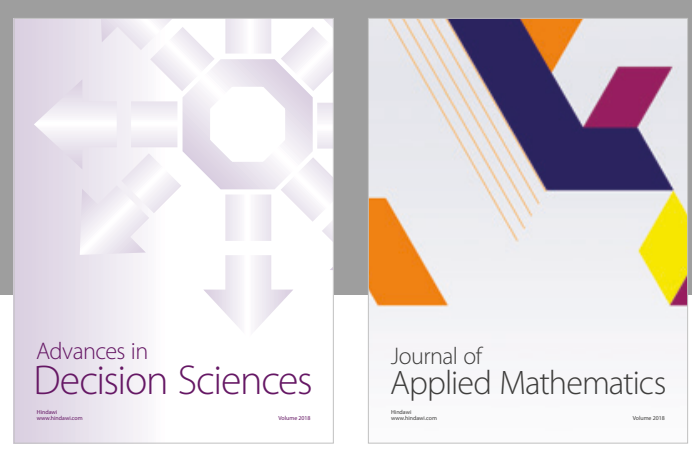

Journal of

Applied Mathematics
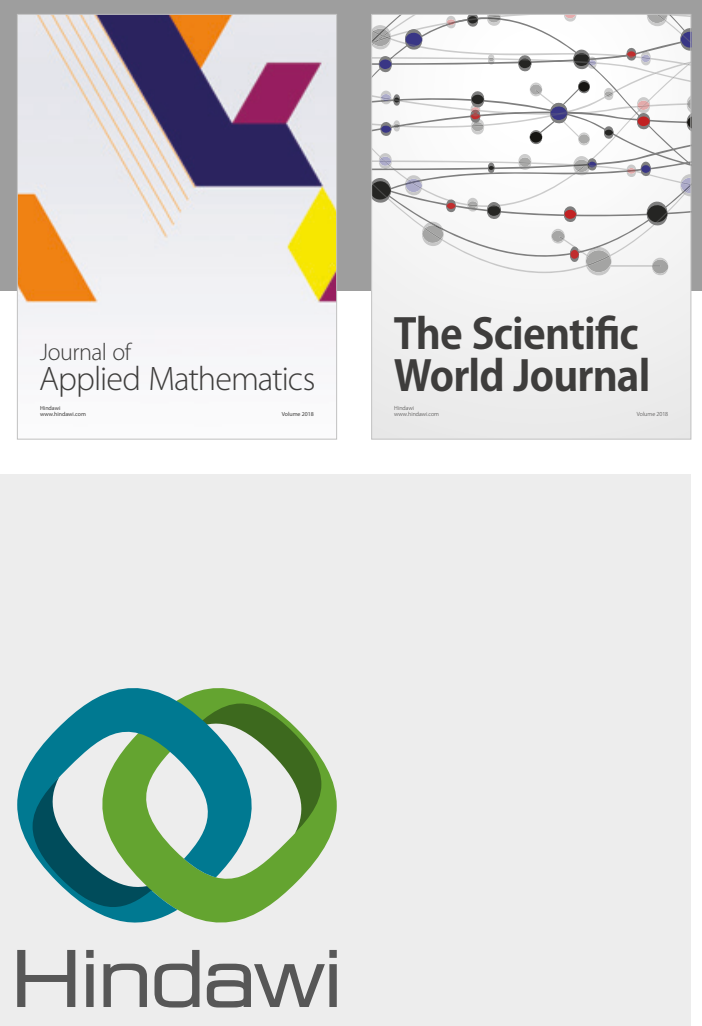

Submit your manuscripts at

www.hindawi.com

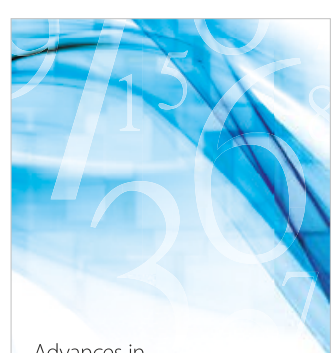

Advances in
Numerical Analysis
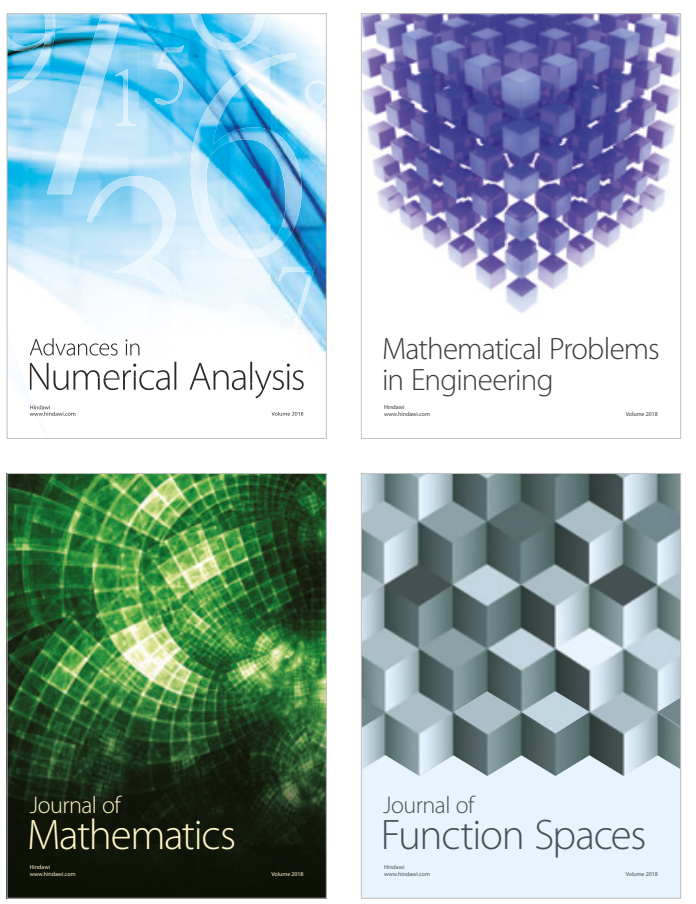

Mathematical Problems in Engineering

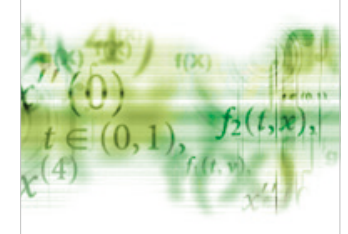

International Journal of

Differential Equations

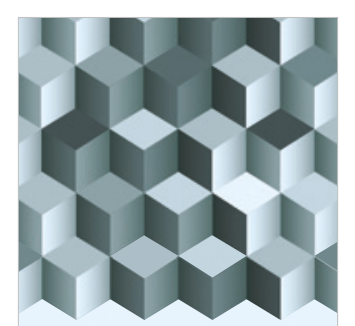

Journal of

Function Spaces

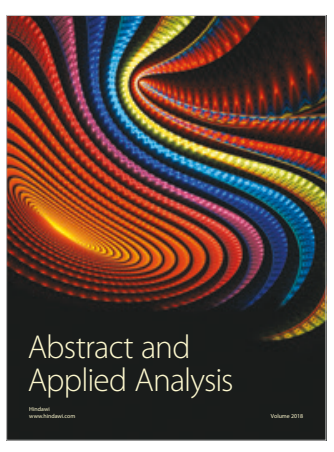

The Scientific

World Journal

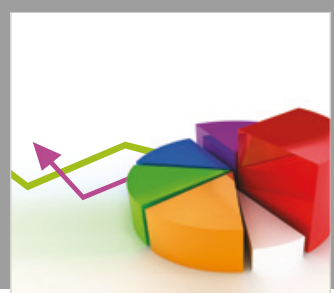

Journal of

Probability and Statistics
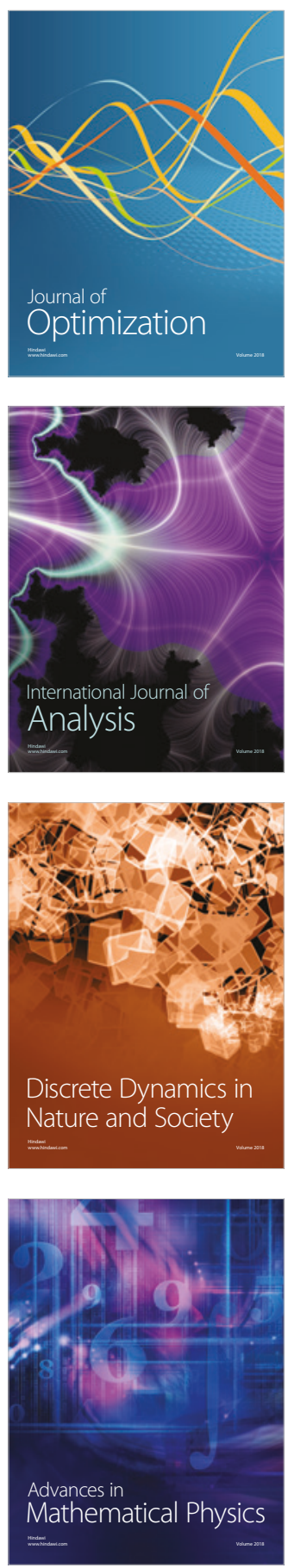